NBER WORKING PAPER SERIES

\title{
EFFECTS OF THE COVID-19 PANDEMIC ON \\ OUTPATIENT PROVIDERS IN THE US
}

\author{
Pinka Chatterji \\ Yue Li \\ Working Paper 27173 \\ http://www.nber.org/papers/w27173 \\ NATIONAL BUREAU OF ECONOMIC RESEARCH \\ 1050 Massachusetts Avenue \\ Cambridge, MA 02138 \\ May 2020
}

The views expressed herein are those of the authors and do not necessarily reflect the views of the National Bureau of Economic Research.

At least one co-author has disclosed a financial relationship of potential relevance for this research. Further information is available online at http://www.nber.org/papers/w27173.ack

NBER working papers are circulated for discussion and comment purposes. They have not been peer-reviewed or been subject to the review by the NBER Board of Directors that accompanies official NBER publications.

(C) 2020 by Pinka Chatterji and Yue Li. All rights reserved. Short sections of text, not to exceed two paragraphs, may be quoted without explicit permission provided that full credit, including () notice, is given to the source. 
Effects of the COVID-19 Pandemic on Outpatient Providers in the US

Pinka Chatterji and Yue Li

NBER Working Paper No. 27173

May 2020

JEL No. I0

\title{
$\underline{\text { ABSTRACT }}$
}

There is growing concern that the COVID-19 pandemic may have severe, adverse effects on the health care sector, a sector of the economy that historically has been somewhat shielded from the business cycle. In this paper, we study one aspect of this issue by estimating the magnitude of the COVID-19 pandemic on use of outpatient health services. We use 2010-2020 data from the Outpatient Influenza-like Illness Surveillance Network (ILINet). Our findings indicate that the COVID-19 pandemic is associated with about a 67 percent decline in the total number of outpatient visits per provider by the week of April 12-18th, 2020 relative to the same week in prior years. Effects become apparent earlier in the pandemic for outpatient visits for non-flu symptoms, but we find negative effects on outpatient visits for flu symptoms as well.

\author{
Pinka Chatterji \\ State University of New York at Albany \\ Economics Department \\ 1400 Washington Avenue \\ Albany, NY 12222 \\ and NBER \\ pchatterji@albany.edu \\ Yue Li \\ Department of Economics \\ SUNY Albany \\ 1400 Washington Avenue \\ Albany, NY 12222 \\ USA \\ yli49@albany.edu
}




\section{Introduction and Background}

As the COVID-19 pandemic ravages the globe, we face simultaneous health and economic crises on an unprecedented scale. In the absence of a vaccine or an effective treatment, nations around the world have resorted to extreme forms of social distancing - keeping adequate space between individuals - to control the spread of COVID-19. In the US, state and local social distancing efforts have included closing schools and universities, shutting down most businesses, prohibiting gatherings, and, in some states, mandating that people stay at home unless there is an essential need. Social distancing is intended to "flatten the disease curve," or spread the disease incidence over a longer period of time, to ensure that demand for medical care does not exceed health system capacity (Gourinchas, 2020). Social distancing reduced mortality during the Great Influenza Pandemic of 1918-1920 (Barro et al., 2020; Correia et al., 2020), but it is too early to systematically assess its effects on health and mortality in the current COVID-19 pandemic.

The economic ramifications of social distancing are unknown and are likely to be enormous. There is growing consensus that the COVID-19 pandemic will lead to a worldwide recession, partly due to the direct effects of the disease itself, but mostly due to the social distancing efforts that are needed to control spread of the disease and save lives. The pandemic causes the demand for goods and services to decrease because of state and local orders to quarantine and stay at home, as well as because of increased uncertainty, income loss, and fear of contagion. At the same time, the pandemic causes a decrease in the supply of goods and services, due to state and local mandates to close businesses, but also due to sick and dying workers, workers' increased caregiving responsibilities, disruptions in supply chains, and increasing prices of inputs (Gopinath, 2020). The resulting loss of output from these demand-side and supply-side shocks are partly due to the disease itself, and would occur even in the absence of social 
distancing. The larger effects on output, however, are likely to be due not to the virus itself but rather to social distancing, one of the only tools we have at our disposal to save lives (Gourinchas, 2020).

One important aspect of the coming COVID-19 recession is that it may affect sectors of the economy that historically have been somewhat shielded from the business cycle. In particular, the health care sector in the US has been relatively insulated from recessions since “...people get sick during both good and bad times..."1 and because health insurance lowers the price of medical care, protecting access to care to some extent for insured patients during economic downturns (Cutler, 2020). Particularly in recent years, the US health care sector has been considered to be "recession resistant" due to the aging of the population, the passage of the 2010 Affordable Care Act, and the fact that this sector of the economy performed well even during the Great Recession in 2007-2009 (Dolfman et al., 2018). But in the current pandemic, the situation appears to be starkly different, particularly for providers in outpatient settings. Social distancing, fear of contagion, quarantining of providers, and other factors appear to be drastically reducing physician visits, putting severe financial strain on outpatient providers. On the supply side, there is concern that primary care -- our front lines in the war against COVID-19 -- may be on the edge of financial disaster (Mostashari, 2020; Abelson, 2020).

On the demand side, if patients delay needed outpatient care due to the pandemic, they may face serious and costly adverse outcomes in the future. In the popular press, there is concern that fear of contagion is delaying childhood immunizations, and preventing individuals with chronic health conditions, as well as serious medical events, from getting care (Hollander, 2020;

\footnotetext{
${ }^{1}$ It is important to note that there is a large literature by Chris Ruhm $(2000,2003,2005,2012,2015,2016)$ and others on the relationship between the business cycle and health outcomes. This body of work will be quite relevant to the current economic crisis caused by COVID-19, but it is outside the scope of the current paper.
} 
CNBC, 2020; Kasanagottu, 2020). In addition, on March 18, 2020, the Centers for Medicare and Medicaid Services (CMS) recommended that all elective and non-urgent surgery and procedures should be delayed during the COVID-19 pandemic to preserve resources and prevent the spread of disease (CMS, 2020). This action has unknown consequences for health outcomes.

It is too early to measure the effects of pandemic-induced reductions in health services use on subsequent health and economic outcomes. The first step is to estimate the magnitudes of these effects. To our knowledge, a study by Mehrotra et al. (2020) is the only existing analysis of the effects of COVID-19 on outpatient services use in the US. These authors use data collected from a national health care technology company that covers more than 50,000 providers. They find that the number of outpatient visits declined sharply in mid-March and remained around this level in the first few weeks of April, compared to a baseline of March 1-7, 2020. For the week ending in 4/18, in-person visits had declined 67 percent and the decline in total visits with telemedicine included was 54 percent (Mehrotra et al., 2020). The authors report larger declines in the Mid-Atlantic and New England regions vs. other regions, increasing use of telemedicine, larger effects on school-aged children and older adults, and larger effects on surgical/procedural specialties, which are impacted by cancellations of elective surgeries (Mehrotra et al., 2020). In this paper, we build on this research by providing regression-based estimates of the impact of the COVID-19 pandemic on health care utilization in the outpatient setting. Using national data from the Outpatient Influenza-like Illness Surveillance Network (ILINet), we test whether the total number of visits per outpatient provider, the number of visits for flu-like symptoms, and the number of visits for other conditions differed in the weeks of the COVID-19 crisis compared to the same weeks prior years, controlling for potentially confounding trends. 
Controlling for trends is important given that researchers have documented a national declining trend in primary care visits since 2008 (Ganguli et al., 2019).

Our findings indicate the COVID-19 pandemic is associated with about a 67 percent decline in the total number of outpatient visits per provider by the middle of April (the week of April 12-18th) 2020 relative to the same week in prior years. Effects become apparent earlier in the pandemic for visits for non-flu symptoms, but we find negative effects on visits for flu symptoms as well.

\section{Methods}

We quantify the effect of the COVID-19 pandemic on outpatient care visits by estimating Equation 1 below.

$$
\frac{\text { Visits }_{\mathrm{iwt}}}{\text { Provider }_{\mathrm{iwt}}}=\sum_{\mathrm{j}} \beta_{j} \text { year } 2020 \text { week }_{j}+\delta_{w}+\delta_{i}+\text { fluseason }_{w t}+\varepsilon_{i w t}
$$

The dependent variable is a measure of the number of outpatient visits per health care provider in state $i$ in week $w$ in year $t$. We use this variable in its natural units, as well as a logged version. On the right-hand side of the model, we include indicators for state $\left(\delta_{i}\right)$, week $\left(\delta_{w}\right)$, and flu season (fluseason ${ }_{w t}$, each flu season starts in week 40 and ends in week 39 of the next year). The key regressors (year 2020 week $_{j}$ ) are a set of dummy variables for week indicators: Jan 26

- Feb 22, Feb 23 - Mar 7, Mar 8 - Mar 14, Mar 15- Mar 21, Mar 22 - Mar 28, Mar 29 - Apr 4, Apr 5-Apr 11, and Apr 12-Apr 18. We put four weeks into one block for the period of Jan 26Mar 7, because Covid-19 only had limited impact on US economy prior to Mar 8. The coefficients of interest are $\beta_{j}$, measuring the difference of week block $j$ in year 2020 and the same week block in the prior years. We cluster standard errors $\left(\varepsilon_{i w t}\right)$ at the state-flu season level 
to account for the correlation of error terms within state and flu season. ${ }^{2}$ We weighted each state by their population and find similar results using unweighted data (unweighted findings not shown).

\section{The Outpatient Influenza-like Illness Surveillance Network (ILINet)}

ILINet is one component of the national flu surveillance system run by the Centers for Disease Control and Prevention (CDC) in collaboration with a variety of agencies and organizations at the state and local level. ${ }^{3}$ The broad goals of CDC's flu surveillance program are to collect data year-round on what flu viruses are in circulation, where and when flu cases are occurring, how the virus may be changing, and the effects of flu on death rates, hospitalizations and outpatient visits (CDC, 2020). ILINet spans all 50 states, the District of Columbia, the US Virgin Islands and Puerto Rico. It is a surveillance effort focused specifically on outpatient providers, which include private practices of any specialty (e.g., family practice, internal medicine, pediatrics), public health clinics, employee health centers, university health centers, emergency departments, and urgent care clinics. In 2018-19, providers in these settings reported on about 60 million patient encounters (CDC, 2020).

The surveillance period starts in week 40 of each year (typically the first week of October) and continues until the start of the subsequent flu season in the following year (MA, 2020). In a typical week, a total of about 2,600 sentinel providers participate in ILINet data collection (CDC, 2020). Sentinel providers provide data every week on the total number of patients seen at their practice for any reason during that week, as well as the total number of

\footnotetext{
${ }^{2}$ We also try one way clustering at the state level, or flu season level, and two way clustering on state and flu season, and results are similar.

${ }^{3}$ ILINet data are available at: https://gis.cdc.gov/grasp/fluview/fluportaldashboard.html.
} 
patients seen specifically for influenza-like symptoms (ILI), which are defined as a fever (temperature of $100^{\circ} \mathrm{F}\left[37.8^{\circ} \mathrm{C}\right]$ or greater) and a cough and/or a sore throat without a known cause other than influenza (CDC, 2020). Providers report these aggregated numbers by age category of the patient ( $0-4$ years, 5-24 years, $25-49$ years, $50-64$ years, and $\geq 65$ years), (researchers cannot access age-specific data) (CDC, 2020). Even if no patients are seen or no patients with ILI are seen, providers are still asked to report zeros into the system (MA, 2020). Some outpatient providers manually input this information into a computer portal every week, while others submit electronic records using a definition for ILI that is determined by state public health agencies. ${ }^{4}$ ILINet data are transmitted directly to the CDC. Data entry by providers has been estimated to take about 30 minutes per week (Immunization Coalition of Delaware, 2020; MA 2020).

The advantage for our study is ILINet data are available on a weekly basis, and the data are released quickly. Our study draws on data from Oct 9, 2010 to April 18, 2020 (Week 16 of the year 2020). Even so, there are two important limitations of these data. First, although we have information on the number of ILINet providers by state by week, we do not know the mix of provider types. States differ in the composition of sentinel providers participating in ILINet, and these differences are likely to affect the number of total visits and the number of ILI visits reported. For example, a state that has many university health centers as sentinel providers typically may report more ILI cases than other states simply because ILI is highly prevalent among college-age people. Continuing with this example, such states also may report lower rates of ILI visits during the COVID-19 pandemic since most university health centers have closed.

On the left-hand side vertical axis, Figure 1 shows trends in the total number of ILINet

\footnotetext{
${ }^{4}$ Data also can be submitted via fax, telephone, or via an e-mailed report. See file://C:/Users/pchat/Downloads/6_Russin_ILINet\%202017\%20basics.pdf for an example from Texas.
} 
providers in the first sixteen weeks of the year for each year from 2011 to $2020 .{ }^{5}$ On the righthand side axis, Figure 1 also plots the number of new confirmed cases of COVID-19 by week for the year 2020. In Figure 1, we observe that since around the $11^{\text {th }}$ week (the week of March $8^{\text {th }}$ ) of 2020, the number of sentinel providers has fallen relative to prior years. This decline is perhaps due to office closings (e.g., university health centers), time demands, and other factors related to the coincident surge in confirmed COVID-19 cases, which also is shown in the figure. ${ }^{6}$

In the models, we partly address this issue by using the total number of visits per provider or the log of this ratio, rather than the total number of visits, as the dependent variable. The state fixed effects in the models capture any time-invariant differences in sentinel provider mixes across states. Also, we estimate some models with only two years of data (2019 and 2020) to greatly reduce the likelihood that state-level, time-varying changes in the sentinel provider mix drive our findings. Further, in some specifications, we include state-specific time trends. Since we cannot identify the type of provider, however, we cannot test for potentially different effects of the COVID-19 pandemic on different types of providers.

A second limitation of the data is it is not clear whether states are including telehealth visits in the number of visits that they are reporting each week. ${ }^{7}$ The ILINet directions ask providers to report on the "total number of patients seen" and it is not specified whether or not these patients need to be seen in person. To our knowledge, there are no state-level estimates of the percent of outpatient providers using videoconferencing for patient visits. As of 2016,

\footnotetext{
${ }^{5}$ We omit data from 2010 because we only have week 40 and later data for that year.

${ }^{6}$ We e-mailed 34 state health departments (including DC) that have publicly available email addresses to request information as to reasons why ILINet participation has fallen during the COVID-19 pandemic. Common reasons cited include: university health centers have closed, and providers have other time commitments or have been moved to other COVID-19 related duties.

${ }^{7}$ E-mails to state health departments revealed that some states are including telemedicine, while others either are not including telemedicine or do not know whether or not this is happening.
} 
however, only 13 percent of physicians worked in practices in which videoconferencing was used for patient encounters, and use of telemedicine tended to be higher in larger practice settings (Kane \& Gillis, 2018). There is variation in state-level policies related to telemedicine and this variation may be related to telemedicine adoption among outpatient providers. ${ }^{8}$ For example, as of 2019, six states had passed telemedicine parity laws, which mandate that private insurance plans reimburse providers equally for services provided via telemedicine vs. the same services provided in person (CCHPCA, 2020). We estimated Equation 1 in sub-samples of states with and without parity laws, but did not find evidence that telemedicine laws affected the impact on outpatient providers during the pandemic (results available upon request).

On the left-hand side vertical axis, Figure 2 shows trends in the total number of ILINet visits per provider in the first sixteen weeks of the year for each year from 2011 to 2020. On the right-hand side axis, Figure 2 also plots the number of new confirmed cases of COVID-19. In each of the years prior to 2020, there is no obvious pattern in the total number of visits per provider during the first sixteen weeks of the year. In 2020, however, one observes a sharp dip in the number of visits per provider starting around the $12^{\text {th }}$ week of the year (the week of March $\left.15^{\text {th }}\right)$. Unsurprisingly, this dip in the number of visits per provider corresponds to the same week in which there is a massive increase in the number of COVID-19 confirmed cases (right-hand side vertical axis). Note that the trend line for number of visits per provider in 2020 lies above the trend lines for the prior years, probably because of the particularly bad flu season in 2020 that preceded the COVID-19 crisis.

\footnotetext{
${ }^{8}$ All Medicaid fee-for-service (FFS) programs in the 50 states and in DC reimburse providers for live telemedicine visits, but private insurers vary in what types of services are reimbursed and the reimbursement rates for telemedicine. During the COVID-19 pandemic, the Centers for Medicare and Medicaid Services as well as commercial insurance companies have been revising payment structures for telemedicine to accommodate the new situation (Hollander \& Carr, 2020).
} 


\section{Results}

Table 1 shows descriptive statistics for our sample. The mean total number of visits per provider per week is 400 , with the $10^{\text {th }}$ percentile equal to 161 visits and the $90^{\text {th }}$ percentile equal to 694 visits. These numbers are large because some of these outpatient providers are emergency departments and university health centers. The average number of ILI visits per provider was about 8 , with the $10^{\text {th }}$ percentile equal to about 0.4 and the $90^{\text {th }}$ percentile equal to about 17 . This variation is likely due to the diversity of the providers included in the ILINet program. The mean number of providers reporting in a typical week was 36.

Table 2 shows regression findings based on our main specification. Columns 1-3 show results for the dependent variable in its natural units, while columns 4-6 show findings based on a logged version of the dependent variable. Based on column 1, we see that until the week of March $15^{\text {th }}$, there were no differences in the total number of visits per provider in 2020 vs. in 2011-2019. The estimated coefficients for these weeks are positive in sign, but they are not statistically different from zero. Starting in the week of March $15^{\text {th }}$, however, we see a sharp reduction of 124 visits in the number of visits per provider (Column 1, Table 2). This negative effect on the number of visits per provider increases in magnitude over time until the week of April $5^{\text {th }}$, and then decreases slightly during the week of April $12^{\text {th }}$.

In columns 2-3, we break down the dependent variable (total number of visits) into visits for ILI and visits for non-ILI. This is important because one might expect that, during the COVID-19 pandemic, people experiencing ILI would be likely visit to outpatient providers out of concern that they have COVID-19 (which has the same symptoms as ILI). That is, one might expect different effects for patients with and without ILI. In columns 2-3, we see that for both ILI and non-ILI visits, there are sudden, large reductions in April 2020. Before April 2020, 
however, there is a strikingly different pattern for ILI vs. non-ILI visits. For ILI visits, there is a statistically significant increase in the number of visits per provider from the week of January $26^{\text {th }}$ to the week of March $15^{\text {th }}, 2020$, while this is not true for non-ILI visits during this time period. These positive coefficients for ILI visits are probably capturing the effects of the particularly bad flu season that preceded the 2020 COVID-19 pandemic. It also appears that the reduction in visits for ILI starts in April, while it starts during the week of March $15^{\text {th }}$ for non-ILI visits. This perhaps is because patients view visits for non-ILI symptoms as more discretionary compared to visits for ILI.

Columns 4-6 of Table 2 show results from models in which the dependent variable is logged; thus, these coefficient estimates can be interpreted as percent changes. From these columns, one can see that the percent drop in outpatient visits started with a sudden, approximately 32 percent drop in total visits per provider in the week of March $15^{\text {th }}$. Over time, this magnitude increased and, as of the week of April $12^{\text {th }}$, the total number of outpatient visits in 2020 was 67 percent lower than in the same week in prior years.

One important threat to these analyses is potentially confounding state-specific trends. In Table 3, we show the same models estimated on data from 2018-2020 flu seasons only (Table 2 draws on ILINet data from 2010-2020 flu seasons). Using a much shorter time period limits the possibility that time trends which vary by state may be driving our findings. The general pattern of findings remains the same in Table 3, with one exception. We no longer see the statistically significant positive coefficients which captured the strong flu season in early 2020, and the magnitudes of the negative effects on ILI visits are even stronger in Table 3. In Appendix Table 1, we explicitly include state-specific time trends in the models. These findings are very similar to our main results in Table 3. 
We consider two other robustness checks of our findings. In Appendix Figures 1-3, we show results from a placebo exercise in which we replace the interactions of "week block" with “year 2020" with interactions of the same week blocks with other years (in other words, we estimate Equation 1 with different sets of interactions). The figures plot the coefficient of the Week 16 interaction term (in the figures, each plotted point comes from a different regression). The figures show no evidence of an effect of these using false pandemic dates. Finally, in Appendix Table 2, we estimate the main models from Table 3 on national ILINet data, rather than on state-level data. There are no appreciable differences from our main findings in Table 2.

\section{Discussion and conclusions}

Our findings show that one by-product of the COVID-19 pandemic in the US is a sudden, large decline in the use of outpatient care. The magnitude of the drop - which so far has increased from 33 percent during the week of March 15th to 67 percent in the week of April $12^{\text {th }}$ - is unparalleled. It is hard to fathom the impact of this reduction on outpatient providers and their patients. Will patients, particularly patients with chronic health conditions, suffer adverse and costly health outcomes later due to the lapse in care? What will be the financial impact on providers, particularly small practices? Will telemedicine fill the gap if fear of contagion is driving these effects?

While our data cannot shed light on mechanisms, the large decline in outpatient care usage that we document is likely driven by factors on both the demand and the supply side related to social distancing. As states start to loosen social distancing restrictions, we may observe an increase in outpatient care due to pent-up demand. It is important to study these changes and, as we adjust to a post-pandemic world, it will be critical to study the longer-term 
effects on not just health service usage but also on health and the health care system (Cutler et al., 2020). 


\section{References}

Abelson, R. (May 5, 2020). Doctors without patients - 'Our waiting rooms are like ghost towns.' The New York Times, Available at: https://www.nytimes.com/2020/05/05/health/coronavirusprimary-care-doctor.html?action=click\&module=Top\%20Stories\&pgtype=Homepage

Barro, R.J., Ursua, J.F. \& Weng, J. (March 2020). The Cornavirus and the Great Influenza Pandemic: Lessons from the Spanish Flu for the Cornavirus' Potential Effects on Mortality and Economic Activity. NBER working paper 26866. Available at: https://www.nber.org/papers/w26866.pdf. Accessed 4/2020.

Center for Connected Health Policy (CCHPCA), (2019). State telehealth laws, Available at: https://www.cchpca.org/sites/default/files/201910/50\%20State\%20Telehalth\%20Laws\%20and\%20Reibmursement\%20Policies\%20Report\%20 Fall\%202019\%20FINAL.pdf. Accessed 4/2020.

Centers for Medicare and Medicaid Services (CMS) (March 18, 2020). CMS releases recommendations on adult elective surgeries, non-essential medical, surgical, and dental procedure during the COVID-19 response. Available at: https://www.cms.gov/newsroom/pressreleases/cms-releases-recommendations-adult-elective-surgeries-non-essential-medical-surgicaland-dental. Accessed: 5/2020.

Centers for Disease Control and Prevention (CDC), 2020. U.S. influenza surveillance system: Purpose and methods. Available at: https://www.cdc.gov/flu/weekly/overview.htm. Accessed $4 / 2020$.

Correia, S., Luck, S., \& Verner, E. (April 10, 2020). Pandemics depress the economy, public health interventions do not: Evidence from the 1918 flu. Available at: https://papers.ssrn.com/sol3/papers.cfm?abstract_id=3561560. Accessed 4/2020.

CNBC. (2020). "Doctors worry the coronavirus is keeping patients away from US hospitals as ER visits drop: 'Heart attacks don't stop.' Available at: https://www.cnbc.com/2020/04/14/doctors-worry-the-coronavirus-is-keeping-patients-awayfrom-us-hospitals-as-er-visits-drop-heart-attacks-dont-stop.html. Accessed 5/2020.

Cutler, D. (April 9, 2020). “How will COVID-19 affect the health care economy?” JAMA Forum Available at: https://jamanetwork.com/channels/health-forum/fullarticle/2764547. Accessed 4/2020.

Cutler, D., Nikpay, S. \& Huckman, R.S. (May 1, 2020). “The business of medicine in the era of COVID-19.” JAMA. Available at: https://jamanetwork.com/journals/jama/fullarticle/2765668. Accessed 5/2020.

Dolfman, ML, Insco, M, \& Holden, RJ. (June 2018) "Healthcare jobs and the Great Recession," Monthly Labor Review, U.S. Bureau of Labor Statistics, Available at: https://doi.org/10.21916/mlr.2018.17. Accessed 4/2020. 
Ganguli, I., Lee, T.H., \& Mehrotra, A. (June 26, 2019). "Evidence and implications behind a national decline in primary care visits.” Journal of General Internal Medicine 34; 2260-2263.

Gopinath, G. (April 2020). Limiting the economic fallout of the coronavirus with large targeted policies in Mitigating the COVID-19 Crisis - Act Fast and Do Whatever it Takes. Available at: https://voxeu.org/content/mitigating-covid-economic-crisis-act-fast-and-do-whatever-it-takes. Accessed 4/2020.

Gourinchas, P. (March 13, 2020). Flattening the Pandemic and Recession Curves. Available at: https://econfip.org/policy-brief/flattening-the-pandemic-and-recession-curves/. Accessed 4/2020.

Hoffmann, J. (April 23, 2020). "Vaccine rates drop dangerously as parents avoid doctor's visits." The New York Times. Available at: https://www.nytimes.com/2020/04/23/health/coronavirusmeasles-vaccines.html. Accessed 5/4/2020.

Hollander, J.E. \& Carr, B.E. (May 6, 2020). "Virtually perfect? Telemedicine for COVID-19.” The New England Journal of Medicine 382:1679-1681. Available at: https://www.nejm.org/doi/full/10.1056/NEJMp2003539. Accessed 5/2020.

Immunization collation of Delaware, ILINet provider program. Available at: http://www.immunizedelaware.org/2019-2020-flu-season/2017-2018-flu-season/ilinet-providerprogram/. Accessed 4/2020.

Kasanagottu, K. (April 15, 2020). "Don’t delay care for chronic illness over coronavirus. It’s bad for you and for hospitals." Available at: https://www.usatoday.com/story/opinion/2020/04/14/coronavirus-chronic-illness-avoidablehospital-admissions-column/5134473002/. Accessed 5/2020.

Massachusetts state government. Influenza-like illness volunteer surveillance program. Available at: https://www.mass.gov/info-details/influenza-like-illness-volunteer-surveillanceprogram. Accessed 4/2020.

Mehrotra, A., Chernew, M., Linetsky, D., Hatch, H., \& Cutler, D. , "What Impact Has COVID19 Had on Outpatient Visits?," To the Point (blog), Commonwealth Fund, Apr. 23, 2020. Available at: https://doi.org/10.26099/ds9e-jm36. Accessed 4/2020.

Mostashari, F. (April 2, 2020). COVID-19 pushing primary care to brink of collapse. Modern Healthcare Available at: https://www.modernhealthcare.com/opinion-editorial/covid-19-pushingprimary-care-brink-collapse. Accessed 4/2020.

Ruhm C.J. (2000). “Are recessions good for your health?” Quarterly Journal of Economics 115(2): 617-650.

Ruhm C.J. (2003). “Good times make you sick.” Journal of Health Economics 22(4): 637-658.

Ruhm C.J. (2005). "Healthy living in hard times.” Journal of Health Economics 24(2): 341-63. 
Ruhm CJ. (2012). Understanding the relationship between macroeconomic conditions and health. In Elgar Companion to Health Economics, Jones AM (ed.)(2nd edn), Edward Elgar: Cheltenham, UK; 5-14.

Ruhm CJ. (2015). “Recessions, healthy no more?” Journal of Health Economics 42: 17-28.

Ruhm, CJ. (2016). "Health effects of economic crises.” Health Economics; 25 Suppl.: 6-24. 


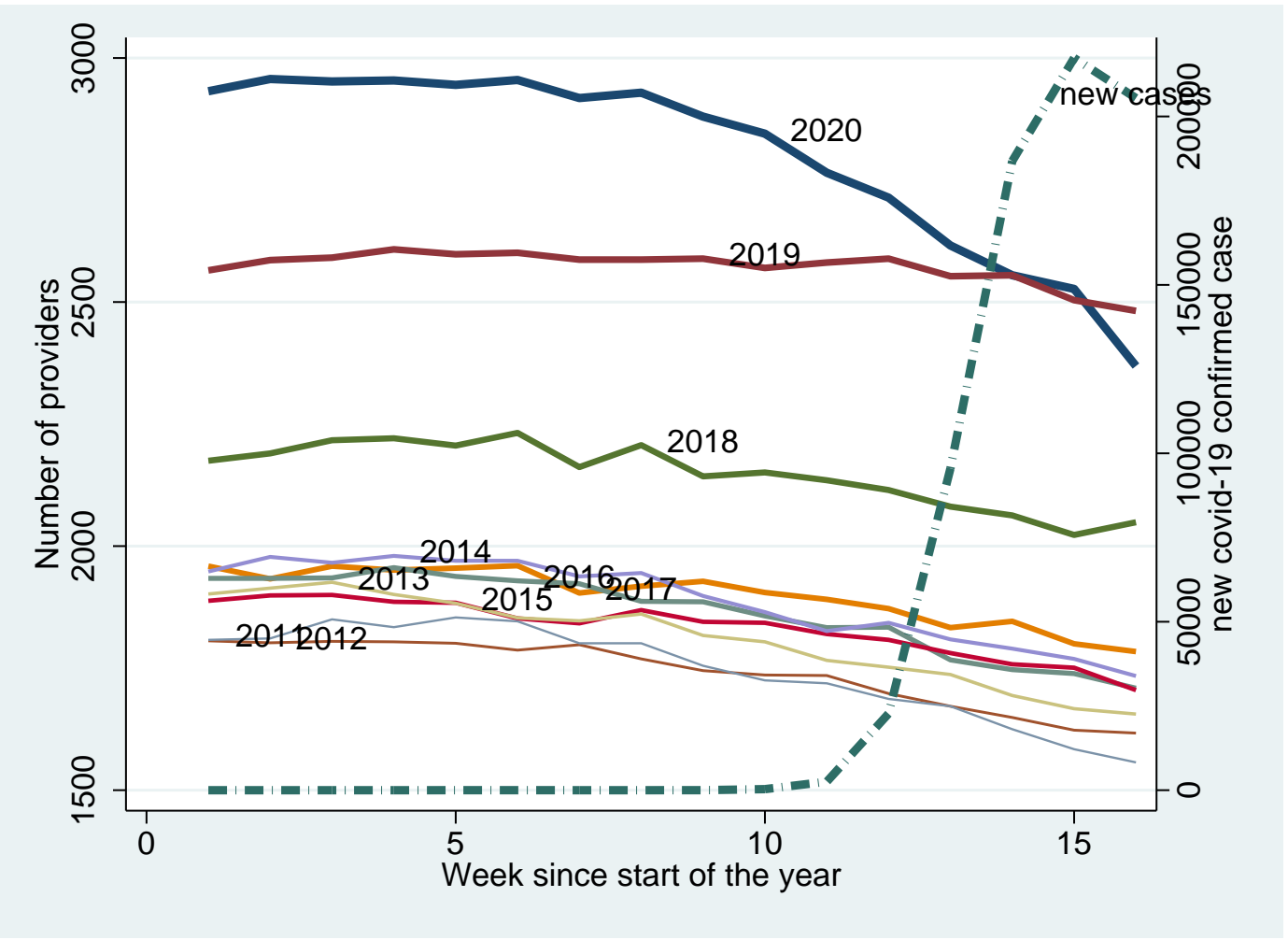

Figure 1: Number of ILINet providers

Source: Data on the number of new COVID-19 confirmed cases come from

https://github.com/CSSEGISandData/COVID-19. Data on the number of providers come from the 20112020 ILINet. Data from 2010 are not included because this year of data starts in Week 40. 


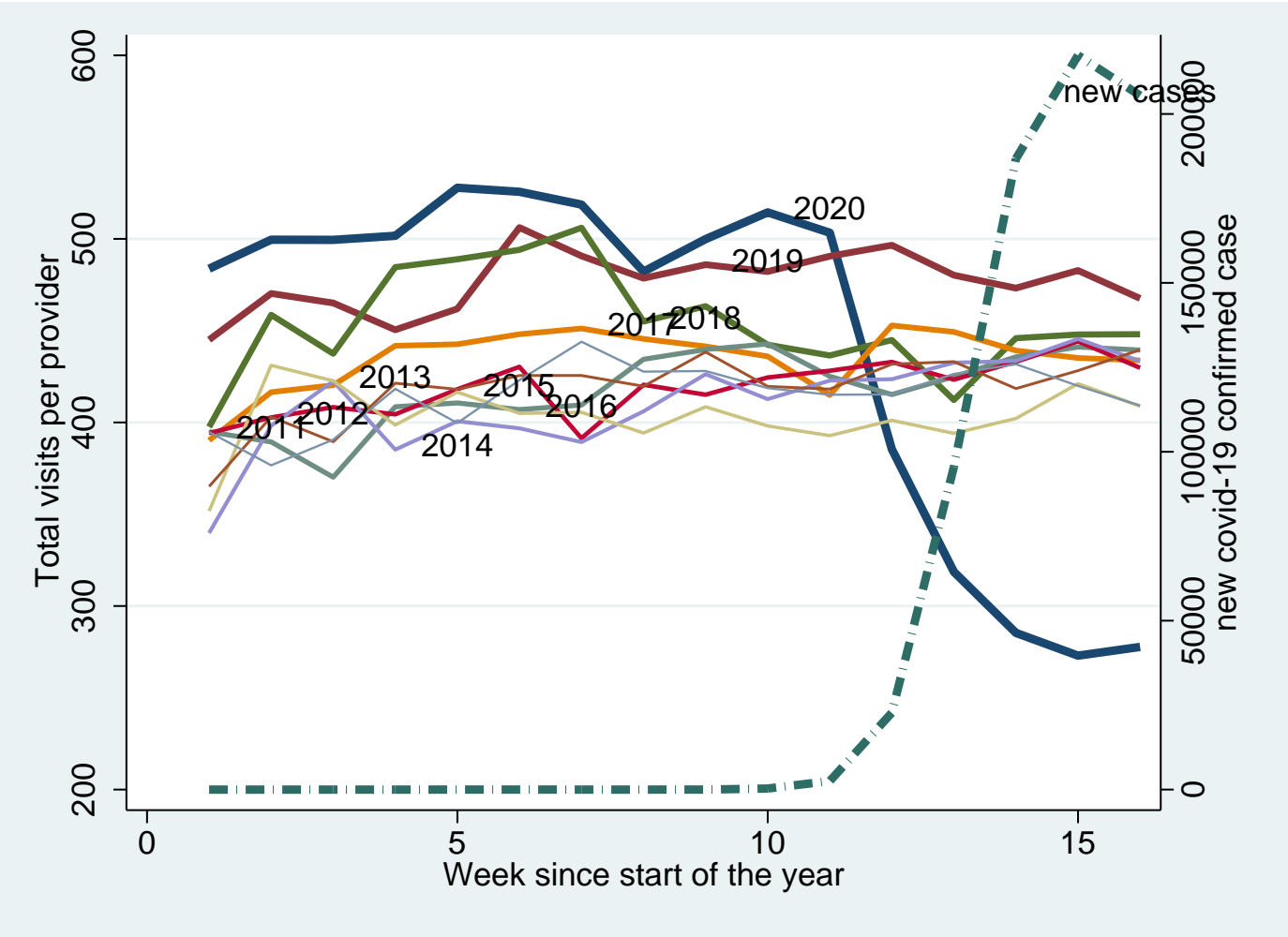

Figure 2: Total outpatient visits per provider

Source: Data on the number of new COVID-19 confirmed cases come from:

https://github.com/CSSEGISandData/COVID-19. Data on the number of providers come from the 20112020 ILINet. Data from 2010 are not included because this year of data starts in Week 40. 


\begin{tabular}{|l|r|r|r|r|r|r|r|}
\hline \multicolumn{8}{|c|}{ Table 1: Weekly summary statistics } \\
\hline & & & \multicolumn{7}{c|}{ Percentiles } \\
\hline & Mean & Std. Dev. & $10 \%$ & $25 \%$ & $50 \%$ & $75 \%$ & $90 \%$ \\
\hline Total visits per provider & 400.4 & 332.2 & 161.2 & 219.8 & 314.2 & 467.8 & 693.8 \\
\hline ILI visits per provider & 7.7 & 11.7 & 0.4 & 1.5 & 4.1 & 9.1 & 17.3 \\
\hline Other visits per provider & 392.7 & 326.2 & 159.4 & 216.3 & 308.7 & 457.9 & 679.6 \\
\hline Number of providers & 36.4 & 36.0 & 7.0 & 14.0 & 24.0 & 46.0 & 83.0 \\
\hline Obs. & \multicolumn{7}{|c|}{24,866} \\
\hline
\end{tabular}

Notes: Data come from 2010-2020 ILINet. 


\begin{tabular}{|c|c|c|c|c|c|c|}
\hline \multicolumn{6}{|c|}{ Table 2: Visits per provider by week, 2010-2020 flu seasons } \\
\hline & $(1)$ & $(2)$ & $(3)$ & $(4)$ & $(5)$ & $(6)$ \\
\hline & \multicolumn{7}{|c|}{ Number } & \multicolumn{3}{c|}{ Log } \\
\hline & Total & ILI & Other & Total & ILI & Other \\
\hline Jan 26 - Feb 22 & 7.824 & $7.395^{* * *}$ & 0.429 & 0.002 & $0.195^{* * *}$ & -0.012 \\
\hline & $(5.802)$ & $(1.561)$ & $(5.528)$ & $(0.013)$ & $(0.060)$ & $(0.013)$ \\
\hline Feb 23 - Mar 7 & 2.043 & $4.870^{* * *}$ & -2.827 & -0.005 & $0.191^{* * *}$ & -0.015 \\
\hline & $(10.078)$ & $(1.066)$ & $(9.660)$ & $(0.020)$ & $(0.067)$ & $(0.020)$ \\
\hline Mar 8 - Mar 14 & 5.074 & $10.859^{* * *}$ & -5.784 & -0.006 & $0.397^{* * *}$ & -0.025 \\
\hline & $(11.758)$ & $(2.087)$ & $(11.404)$ & $(0.029)$ & $(0.080)$ & $(0.030)$ \\
\hline Mar 15 - Mar 21 & $-123.995^{* * *}$ & $9.246^{* * *}$ & $-133.241^{* * *}$ & $-0.316^{* * *}$ & $0.306^{* * *}$ & $-0.348^{* * *}$ \\
\hline & $(13.944)$ & $(3.189)$ & $(14.194)$ & $(0.037)$ & $(0.090)$ & $(0.037)$ \\
\hline Mar 22 - Mar28 & $-180.864 * * *$ & 3.655 & $-184.519^{* * *}$ & $-0.535^{* * *}$ & -0.100 & $-0.557^{* * *}$ \\
\hline & $(12.775)$ & $(4.016)$ & $(13.356)$ & $(0.050)$ & $(0.126)$ & $(0.047)$ \\
\hline Mar 29-Apr 4 & $-214.442 * * *$ & -1.545 & $-212.897^{* * *}$ & $-0.644^{* * *}$ & $-0.447^{* * *}$ & $-0.654^{* * *}$ \\
\hline & $(14.850)$ & $(2.951)$ & $(15.743)$ & $(0.042)$ & $(0.152)$ & $(0.039)$ \\
\hline Apr 5- Apr 11 & $-240.573^{* * *}$ & $-5.065^{* * *}$ & $-235.507^{* * *}$ & $-0.708^{* * *}$ & $-0.648^{* * *}$ & $-0.709^{* * *}$ \\
\hline & $(16.575)$ & $(1.758)$ & $(16.944)$ & $(0.031)$ & $(0.136)$ & $(0.029)$ \\
\hline Apr 12 - Apr 18 & $-229.965^{* * *}$ & $-6.869^{* * *}$ & $-223.096^{* * *}$ & $-0.667^{* * *}$ & $-0.784^{* * *}$ & $-0.662^{* * *}$ \\
\hline & $(19.916)$ & $(1.368)$ & $(19.700)$ & $(0.039)$ & $(0.143)$ & $(0.038)$ \\
\hline R2 & 0.5766 & 0.5641 & 0.5733 & 0.6404 & 0.7057 & 0.6381 \\
\hline Obs & 24866 & 24866 & 24866 & 24866 & 24058 & 24866 \\
\hline
\end{tabular}

Notes: Data come from 2010-2020 ILINet. Table reports the coefficient for the interaction of year 2020 with the indicated week blocks, The regression models also include state indicators, week indicators, and flu season indicators. Table shows estimated coefficients from OLS models with robust standard errors clustered at the state-flu season level. 


\begin{tabular}{|c|c|c|c|c|c|c|}
\hline \multicolumn{7}{|c|}{ Table 3: Visits per provider by week, 2018-2020 flu seasons } \\
\hline & $(1)$ & $(2)$ & $(3)$ & $(4)$ & $(5)$ & $(6)$ \\
\hline & \multicolumn{7}{|c|}{ Number } & \multicolumn{3}{c|}{ Log } \\
\hline & Total & ILI & Other & Total & ILI & Other \\
\hline Jan 26 - Feb 22 & 10.693 & 3.327 & 7.365 & 0.015 & 0.044 & 0.011 \\
\hline & $(6.622)$ & $(2.139)$ & $(5.993)$ & $(0.017)$ & $(0.089)$ & $(0.015)$ \\
\hline Feb 23 - Mar 7 & 1.053 & -1.221 & 2.274 & -0.008 & -0.138 & -0.003 \\
\hline & $(10.828)$ & $(1.567)$ & $(10.428)$ & $(0.024)$ & $(0.095)$ & $(0.024)$ \\
\hline Mar 8 - Mar 14 & -8.754 & $4.528^{* *}$ & -13.282 & -0.033 & -0.022 & -0.037 \\
\hline & $(13.138)$ & $(2.272)$ & $(12.807)$ & $(0.033)$ & $(0.102)$ & $(0.035)$ \\
\hline Mar 15 - Mar 21 & $-135.225^{* * *}$ & 4.294 & $-139.520^{* * *}$ & $-0.331^{* * *}$ & -0.087 & $-0.350^{* * *}$ \\
\hline & $(16.826)$ & $(3.279)$ & $(17.053)$ & $(0.041)$ & $(0.109)$ & $(0.040)$ \\
\hline Mar 22 - Mar28 & $-177.541^{* * *}$ & 0.414 & $-177.954^{* * *}$ & $-0.529 * * *$ & $-0.398^{* * *}$ & $-0.542 * * *$ \\
\hline & $(13.060)$ & $(4.090)$ & $(13.674)$ & $(0.050)$ & $(0.136)$ & $(0.048)$ \\
\hline Mar 29-Apr 4 & $-204.070^{* * *}$ & -4.036 & $-200.033^{* * *}$ & $-0.616^{* * *}$ & $-0.703^{* * *}$ & $-0.618^{* * *}$ \\
\hline & $(15.231)$ & $(3.018)$ & $(16.149)$ & $(0.044)$ & $(0.157)$ & $(0.041)$ \\
\hline Apr 5- Apr 11 & $-235.593^{* * *}$ & $-6.905^{* * *}$ & $-228.688^{* * *}$ & $-0.683^{* * *}$ & $-0.845^{* * *}$ & $-0.678^{* * *}$ \\
\hline & $(19.297)$ & $(1.818)$ & $(19.615)$ & $(0.035)$ & $(0.139)$ & $(0.033)$ \\
\hline Apr 12 - Apr 18 & $-216.804^{* * *}$ & $-7.808^{* * *}$ & $-208.996^{* * *}$ & $-0.623^{* * *}$ & $-0.933^{* * *}$ & $-0.614^{* * *}$ \\
\hline & $(22.817)$ & $(1.530)$ & $(22.481)$ & $(0.046)$ & $(0.150)$ & $(0.045)$ \\
\hline R2 & 0.9084 & 0.7244 & 0.9076 & 0.8561 & 0.8396 & 0.8587 \\
\hline Obs & 4049 & 4049 & 4049 & 4049 & 3989 & 4049 \\
\hline
\end{tabular}

Notes: Data come from 2019-2020 ILINet. Table reports the coefficient for the interaction of year 2020 with the indicated week blocks, The regression models also include state indicators, week indicators, and flu season indicators. Table shows estimated coefficients from OLS models with robust standard errors clustered at the state-flu season level. 


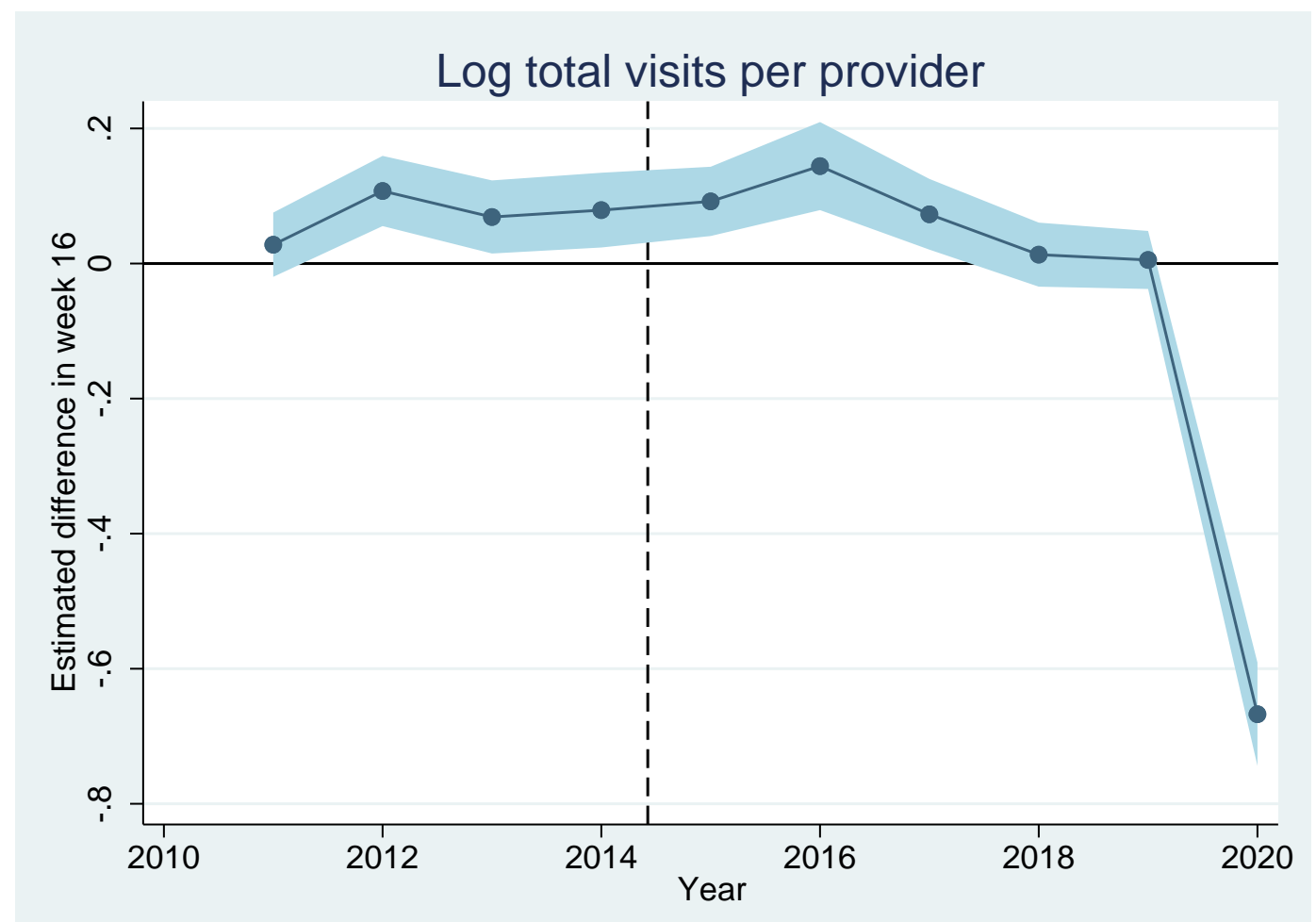

Appendix Figure 1: Placebo test for log total visits

Note: The figure plots the coefficient of interaction between Week 16 and the year (in the figures, each plotted point comes from a different regression). All regression models include state indicators, week indicators, flu season indicators, and interaction terms between a set of week blocks and the year. 


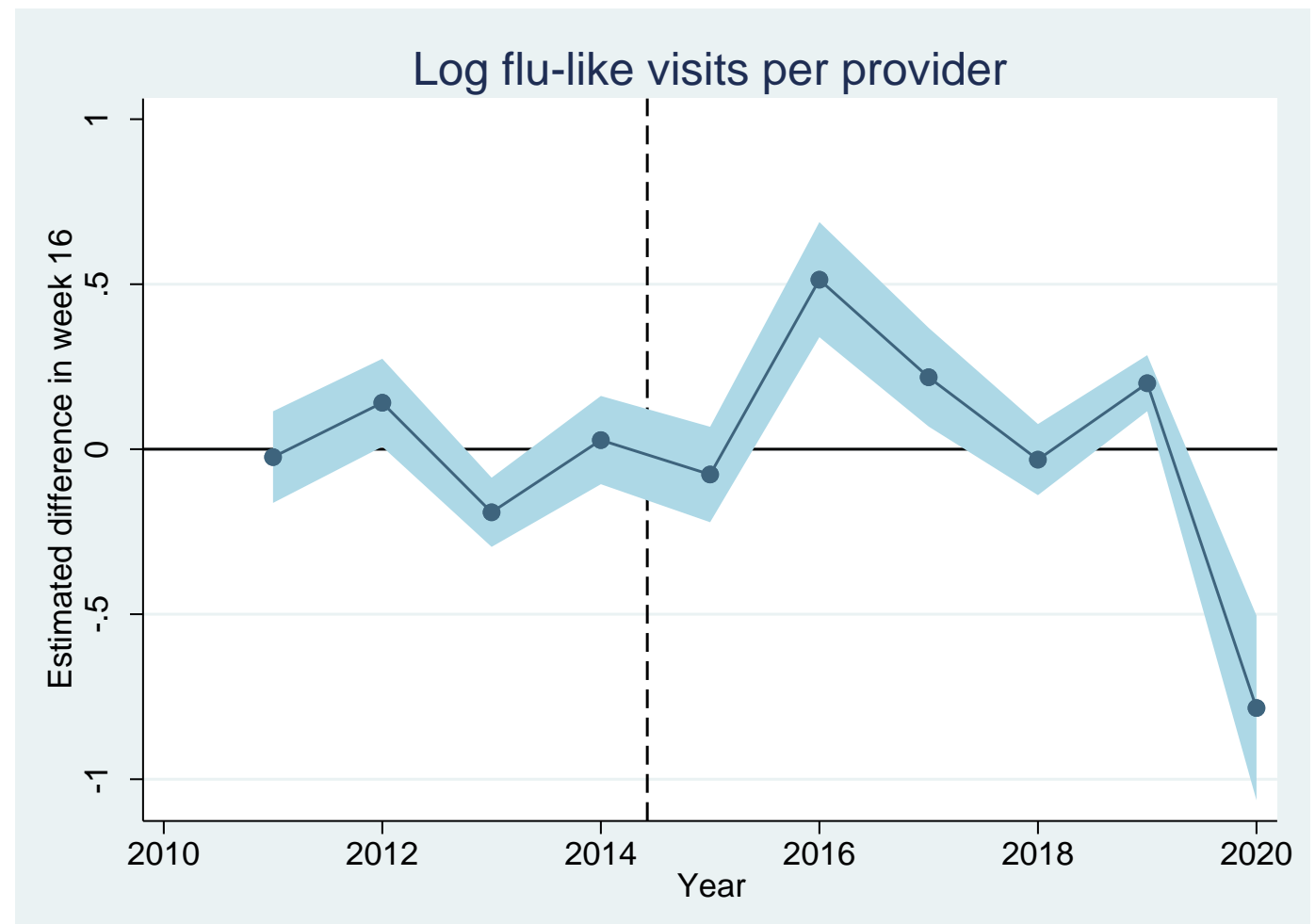

Appendix Figure 2: Placebo test for log ILI visits

Note: The figure plots the coefficient of interaction between Week 16 and the year (in the figures, each plotted point comes from a different regression). All regression models include state indicators, week indicators, flu season indicators, and interaction terms between a set of week blocks and the year. 


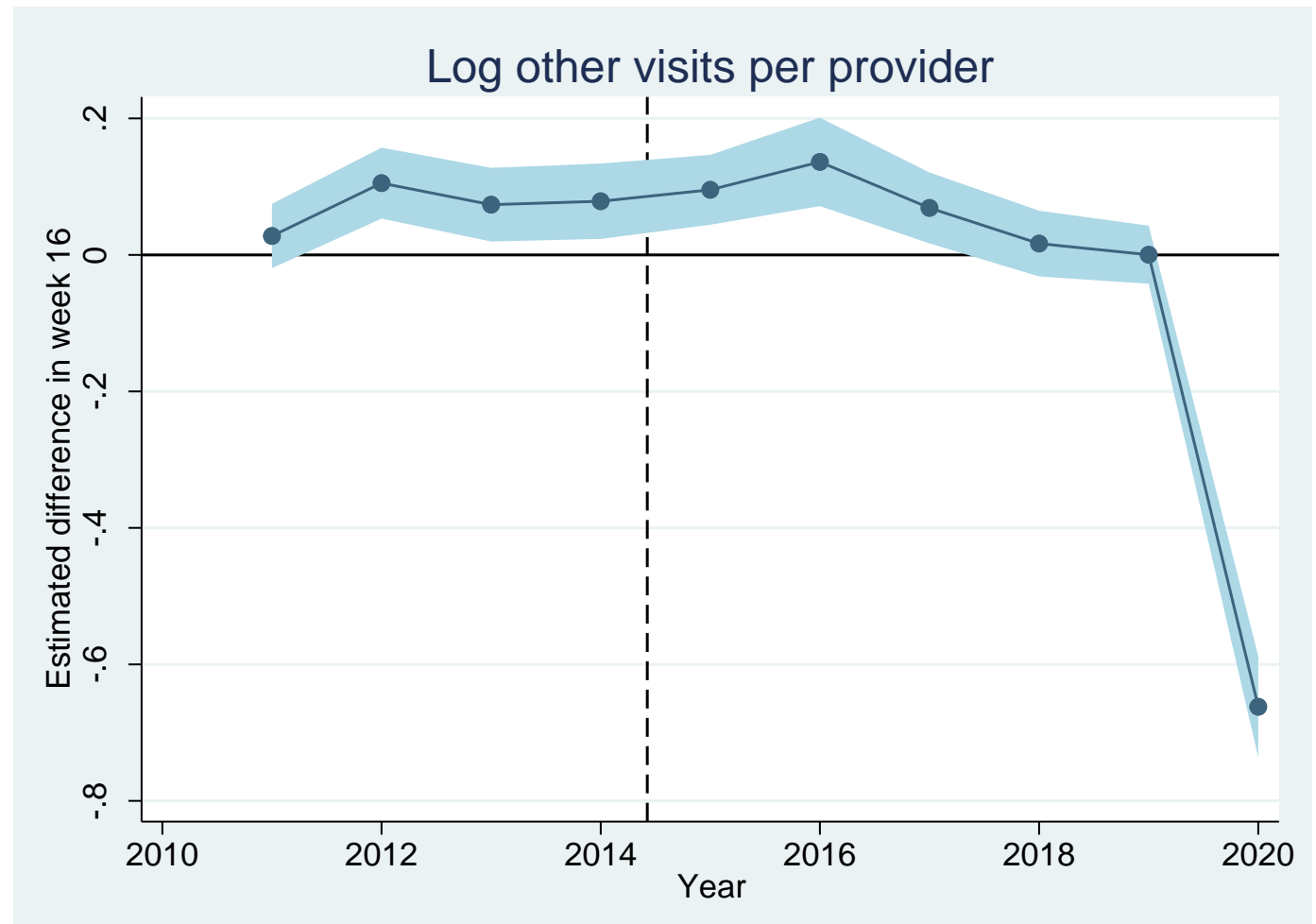

Appendix Figure 3: Placebo test for log non-ILI visits

Note: The figure plots the coefficient of interaction between Week 16 and the year (in the figures, each plotted point comes from a different regression). All regression models include state indicators, week indicators, flu season indicators, and interaction terms between a set of week blocks and the year. 


\begin{tabular}{|c|c|c|c|c|c|c|}
\hline \multicolumn{7}{|c|}{ Appendix Table 1: Models with state-specific trends } \\
\hline & (1) & (2) & (3) & (4) & (5) & (6) \\
\hline & \multicolumn{3}{|c|}{ Number } & \multicolumn{3}{|c|}{ Log } \\
\hline & Total & ILI & Other & Total & ILI & Other \\
\hline \multirow[t]{2}{*}{ Jan 26 - Feb 22} & 6.504 & $7.212 * * *$ & -0.708 & -0.001 & $0.182 * * *$ & -0.015 \\
\hline & $(5.636)$ & $(1.543)$ & $(5.427)$ & $(0.014)$ & $(0.059)$ & $(0.013)$ \\
\hline \multirow[t]{2}{*}{ Feb 23 - Mar 7} & 0.723 & $4.687 * * *$ & -3.964 & -0.008 & $0.178 * * *$ & -0.018 \\
\hline & $(10.028)$ & $(1.080)$ & $(9.598)$ & $(0.021)$ & $(0.067)$ & $(0.021)$ \\
\hline \multirow[t]{2}{*}{ Mar 8 - Mar 14} & 3.754 & $10.675^{* * *}$ & -6.921 & -0.009 & $0.384^{* * *}$ & -0.028 \\
\hline & $(10.847)$ & $(2.044)$ & $(10.689)$ & $(0.027)$ & $(0.077)$ & $(0.028)$ \\
\hline \multirow[t]{2}{*}{ Mar 15 - Mar 21} & $-125.315^{* * *}$ & $9.063 * * *$ & $-134.378 * * *$ & $-0.319 * * *$ & $0.292 * * *$ & $-0.350 * * *$ \\
\hline & $(15.238)$ & $(3.150)$ & $(15.617)$ & $(0.040)$ & $(0.088)$ & $(0.040)$ \\
\hline \multirow[t]{2}{*}{ Mar 22 - Mar28 } & $-182.185^{* * *}$ & 3.472 & $-185.656 * * *$ & $-0.538 * * *$ & -0.113 & $-0.559 * * *$ \\
\hline & $(13.427)$ & (3.979) & $(14.251)$ & $(0.048)$ & $(0.124)$ & $(0.046)$ \\
\hline \multirow[t]{2}{*}{ Mar 29-Apr 4} & $-215.762 * * *$ & -1.728 & $-214.034^{* * *}$ & $-0.647 * * *$ & $-0.461 * * *$ & $-0.656 * * *$ \\
\hline & $(15.758)$ & (2.915) & $(16.776)$ & $(0.039)$ & $(0.149)$ & $(0.037)$ \\
\hline \multirow[t]{2}{*}{ Apr 5-Apr 11} & $-241.893 * * *$ & $-5.249 * * *$ & $-236.644 * * *$ & $-0.711 * * *$ & $-0.663 * * *$ & $-0.712 * * *$ \\
\hline & $(18.001)$ & $(1.734)$ & $(18.407)$ & $(0.028)$ & $(0.133)$ & $(0.027)$ \\
\hline \multirow[t]{2}{*}{ Apr 12 - Apr 18} & $-231.286 * * *$ & $-7.053 * * *$ & $-224.233 * * *$ & $-0.670 * * *$ & $-0.799 * * *$ & $-0.665 * * *$ \\
\hline & $(21.078)$ & $(1.374)$ & $(20.883)$ & $(0.035)$ & $(0.139)$ & $(0.035)$ \\
\hline $\mathrm{R} 2$ & 0.7490 & 0.6241 & 0.7463 & 0.7836 & 0.7578 & 0.7833 \\
\hline Obs & 24866 & 24866 & 24866 & 24866 & 24058 & 24866 \\
\hline
\end{tabular}

Notes: Data come from 2010-2020 ILINet. Table reports the coefficient for the interaction of year 2020 with the indicated week blocks, The regression models also include state indicators, week indicators, flu season indicators, and state-specific weekly time trends. Table shows estimated coefficients from OLS models with robust standard errors clustered at the state-flu season level. 


\begin{tabular}{|c|c|c|c|c|c|c|}
\hline \multicolumn{7}{|c|}{ Appendix Table 2: Estimates based on national-level data } \\
\hline & $(1)$ & $(2)$ & $(3)$ & $(4)$ & $(5)$ & $(6)$ \\
\hline & \multicolumn{7}{|c|}{ Number } \\
\hline & Total & ILI & Other & Total & ILI & Other \\
\hline Jan 26 - Feb 22 & 5.911 & $8.477^{* * *}$ & -2.566 & 0.002 & $0.203^{* *}$ & -0.013 \\
\hline & $(11.525)$ & $(2.311)$ & $(9.891)$ & $(0.025)$ & $(0.087)$ & $(0.023)$ \\
\hline Feb 23 - Mar 7 & -2.176 & $5.526^{* * *}$ & -7.702 & -0.015 & $0.186 * *$ & -0.026 \\
\hline & $(10.452)$ & $(1.690)$ & $(9.332)$ & $(0.024)$ & $(0.083)$ & $(0.022)$ \\
\hline Mar 8 - Mar 14 & 1.553 & $12.511^{* * *}$ & -10.959 & -0.005 & $0.485^{* * *}$ & $-0.030^{*}$ \\
\hline & $(7.790)$ & $(1.573)$ & $(7.089)$ & $(0.019)$ & $(0.083)$ & $(0.018)$ \\
\hline Mar 15 - Mar 21 & $-124.150^{* * *}$ & $10.219^{* * *}$ & $-134.369 * * *$ & $-0.290^{* * *}$ & $0.459^{* * *}$ & $-0.330^{* * *}$ \\
\hline & $(7.715)$ & $(1.473)$ & $(6.916)$ & $(0.019)$ & $(0.077)$ & $(0.017)$ \\
\hline Mar 22 - Mar28 & $-186.751^{* * *}$ & $2.749^{* *}$ & $-189.500^{* * *}$ & $-0.471^{* * *}$ & $0.197^{* * *}$ & $-0.501 * * *$ \\
\hline & $(9.153)$ & $(1.386)$ & $(8.407)$ & $(0.022)$ & $(0.072)$ & $(0.021)$ \\
\hline Mar 29-Apr 4 & $-224.085^{* * *}$ & $-2.427^{*}$ & $-221.659 * * *$ & $-0.591^{* * *}$ & -0.066 & $-0.609 * * *$ \\
\hline & $(7.704)$ & $(1.297)$ & $(7.101)$ & $(0.019)$ & $(0.060)$ & $(0.018)$ \\
\hline Apr 5- Apr 11 & $-242.371^{* * *}$ & $-5.835^{* * *}$ & $-236.536^{* * *}$ & $-0.649 * * *$ & $-0.322^{* * *}$ & $-0.655^{* * *}$ \\
\hline & $(8.003)$ & $(1.301)$ & $(7.357)$ & $(0.019)$ & $(0.064)$ & $(0.018)$ \\
\hline Apr 12 - Apr 18 & $-231.385^{* * *}$ & $-7.169^{* * *}$ & $-224.216^{* * *}$ & $-0.617^{* * *}$ & $-0.463^{* * *}$ & $-0.616^{* * *}$ \\
\hline & $(7.786)$ & $(1.312)$ & $(7.052)$ & $(0.019)$ & $(0.066)$ & $(0.018)$ \\
\hline R2 & 0.8297 & 0.7627 & 0.8495 & 0.8179 & 0.8757 & 0.8385 \\
\hline Obs & 498 & 498 & 498 & 498 & 498 & 498 \\
\hline
\end{tabular}

Notes: Data come from 2010-2020 ILINet. Table reports the coefficient for the interaction of year 2020 with the indicated week blocks, The regression models also include week indicators, and flu season indicators. Table shows estimated coefficients from OLS models with robust standard errors. 